\title{
Effect of a Strobilurin-Class Fungicide on Water Use in Synthetic Bread Wheat Genotypes Grown under Increasing Water Deficit Conditions
}

\author{
M.N. INAGAKI ${ }^{1,2} *$ M. MORI ${ }^{1,2}$ and M.M. NACHIT ${ }^{1}$ \\ ${ }^{1}$ International Center for Agricultural Research in the Dry Areas (ICARDA), P. O. Box 5466, Aleppo, Syria \\ ${ }^{2}$ Japan International Research Center for Agricultural Sciences (JIRCAS), Tsukuba, Ibaraki, 305-8686 Japan \\ (Received 16 April 2009; accepted 14 May 2009; \\ Communicated by J. Johnson)
}

\begin{abstract}
Three synthetic bread wheat genotypes and their parental cultivar Cham 6 were used to examine the effects of a strobilurin-class fungicide pyraclostrobin on leaf temperature, root water uptake and grain yield under increasing water deficit conditions. Wheat plants of Cham 6 treated with the pyraclostrobin at the booting stage showed a rapidly increased leaf temperature as compared with the gradually increased leaf temperature of the untreated plants. The final temperature reached, however, was lower for the pyraclostrobin treated plants than the untreated. Potted soil of the treated wheat plants also showed higher water contents than the untreated potted soil, suggesting delay of plant water uptake by pyraclostrobin treatment. A variation in water uptake by roots was also found between the four wheat genotypes examined. Daily water uptake was depressed after the pyraclostrobin treatment in all four wheat genotypes. Grain yields were slightly increased by the pyraclostrobin treatment in field trials under controlled water supply whereas no significant differences were detected in soil water content between treatments. The increase in grain yield by pyraclostrobin treatment might be dependent on the different water uptake of the wheat genotypes. These results suggest that foliage treatment of pyraclostrobin fungicide on wheat delays root water uptake, resulting in postponement of soil dehydration, which contributes to a slight increase of grain yield in some wheat genotypes in the field under water deficit conditions.
\end{abstract}

Keywords: synthetic wheat, pyraclostrobin, strobilurin, leaf temperature, water use, water uptake, drought

\section{Introduction}

In the Mediterranean climate regions of West Asia and North Africa, rainfall concentrates in the period from November to May, which coincides with the growing season of wheat. Wheat growth under rain-fed conditions often suffers from water deficit stress at both ends of the growing season, that is, immediately after germination and after flowering. In the growth period immediately before and after the flowering stage, the rate of water use of wheat plants is particularly critical for the following grain yield formation under in-

* Corresponding author; E-mail: m.inagaki@cgiar.org

0133-3720/\$20.00 C 2009 Akadémiai Kiadó, Budapest 
creasing water deficit stress in the residual soil water (Richards et al. 2002; OlivaresVillegas et al. 2007).

Wheat plants can use more water by means of the enhanced water uptake of roots from soil. Increased water uptake before the flowering stage, however, leaves less available water in grain filling stage, resulting in more severe water deficit stress. Overall plant growth is regulated as a function of plant water uptake and residual soil water. Better understandings of water relations between the soil and plant are therefore a key issue for adaptation of drought tolerant genotypes, in particular, for new synthetic bread wheat genotypes developed for the dry climate regions (Del Blanco et al. 2001; Dreccer et al. 2007; Reynolds et al. 2007). Available soil water is taken up by roots, and transported to the leaves for transpiration during photosynthesis. Under water deficit conditions of soil, however, water uptake is depressed, resulting in less leaf transpiration due to stomatal closure. Leaf temperature is closely related to transpirational cooling of the leaves and can be used as an indicator of water deficit stress. Root water uptake and leaf transpiration are the two factors influencing water use and therefore significantly influence grain filling after flowering under water deficit conditions.

A strobilurin-class fungicide has been extensively utilized for foliar disease control in a wide range of crops worldwide in recent years (Bartlett et al. 2002). In addition, some physiological effects on the inhibition of mitochondrial respiration in cell metabolism, increase of nitrate accumulation in tissue and final increase of biomass and grain yield of wheat has been reported (Köhle et al. 2002). Use of strobilurin which, in addition to its fungicide effect, is an alternative approach to increase and stabilize grain yields of wheat in the dry climate regions. It is, however, not clear how strobilurin treatment influences root water uptake and leaf transpiration for synthetic bread wheats that are differentially adaptable to water deficit stress.

In this study, the effects of a strobilurin-class fungicide pyraclostrobin on leaf temperature, root water uptake and grain yield of synthetic bread wheat genotypes were examined under increasing water deficit conditions.

\section{Materials and Methods}

Leaf temperature and soil water content of wheat plants treated with pyraclostrobin under controlled conditions

Three plants of bread wheat genotype (Triticum aestivum L. cv. Cham 6) with three replicates were grown in potted soil (1100 g dry weight per pot) in a growth chamber with $22 / 10^{\circ} \mathrm{C}$ day/night, 10 -h day-length and $250 \mu \mathrm{mol} \cdot \mathrm{m}^{-2} \cdot \mathrm{s}^{-1}$ light intensity. Soil was a mixture of field soil, sand and peat moss, with a permanent wilting point (PWP) of $14.6 \%$ by weight. Irrigation was periodically performed to hold soil water content ranging between $45.0 \%$ and $25.0 \%$. At the booting stage of growth, wheat plants were treated with a solution of $0.267 \%$ of fungicide pyraclostrobin F $500^{\circledR}$ (BASF Societas Europeae, Germany) or with the equivalent water (control treatment). During the consecutive seven days from treatment, a thermal imaging camera (Nippon Avionics, TVS-200) was used to record the 
thermal image of three treated and three untreated pots in the same frame, as described in a previous paper (Inagaki and Nachit 2008). Leaf temperatures were collected daily from nine individual pixels each in the flag leaves of the wheat plants. At the same time, the soil water contents were obtained by weighing the potted soil.

\section{Water uptake of four wheat genotypes treated with pyraclostrobin}

Three synthetic bread wheat genotypes, SYN-8, SYN-10 and SYN-15, derived from a cross of Cham 6/3/Haurani/Aegilops tauschii ig47259//Cham 6 along with a parental cultivar Cham 6 were used as plant materials. Cham 6 is an improved cultivar of bread wheat and Haurani is a landrace of durum wheat (T. turgidum L. spp. durum). SYN-10 and SYN-15 were selected as tolerant and susceptible to drought in terms of grain yield, respectively, in comparison with SYN-8 and Cham 6 under very dry conditions of an annual rainfall of $300 \mathrm{~mm}$ (Inagaki et al. 2007). Five plants of each wheat genotype were grown in potted soil with three replicates and treated with pyraclostrobin as described above. Irrigation was performed to keep soil water content from $45.0 \%$ to $25.0 \%$. Evaporation from soil surface was estimated by weighing the potting soil without plants. Mean water uptake per day for each genotype was calculated for the first four days after irrigation in the control treatment and pyraclostrobin treatment. It was furthermore expressed as water uptake per pot and water uptake per shoot dry weight.

Yield performance of four wheat genotypes treated with pyraclostrobin under controlled water supply

Four wheat genotypes, SYN-8, SYN-10, SYN-15 and Cham 6, were used as plant materials. The experiment was laid out with three replicates in a randomized complete block design with split-plot arrangement for pyraclostrobin treatment. Wheat materials were grown in $10 \mathrm{~m}^{2}$ field plots each at Tel Hadya station, ICARDA during the 2007/08 cropping season. Irrigation was planned to supply an evapotranspiration estimate of $420 \mathrm{~mm}$ in this area (Zhang et al. 1998) during the period from germination to flowering. At the growth stage of booting, split (adjacent) plots of each wheat genotype were treated with pyraclostrobin or the control treatment (no application). The treatment was performed with $30 \mathrm{ml}(0.267 \%)$ solution, providing $0.08 \mathrm{ml}$ product per $\mathrm{m}^{2}$. Canopy temperature was obtained from thermal images each containing eight plots taken at 12:00 $\mathrm{h}$ at flowering. Water contents of soil layers in depth of $90 \mathrm{~cm}$ was measured monthly by weight in the border plots from germination through to maturity, in addition to the soil water contents in field plots of four wheat genotypes at flowering. The permanent wilting point (PWP) of soil was determined to be $29.8 \%$ using a conventional method (Ryan et al. 1997). After maturity, wheat plants of $6 \mathrm{~m}^{2}$ per plot was harvested, and agronomic data including 1000-kernel weight and grain yield were collected and analyzed. The comparison between wheat genotype means for treatment effect was performed using the least significant difference (LSD) derived from analysis of variance. 


\section{Results and Discussion}

\section{Effects of pyraclostrobin treatment on water use of wheat plants}

Infrared thermographs of bread wheat Cham 6 plants grown in potted soil successfully indicated leaf temperature increases one day after the pyraclostrobin treatment and decreased four days after the treatment, in comparison with the untreated control plants, as visually shown in Figure 1. Figure 2 shows changes of leaf temperature and soil water content for the treatments during the seven days following irrigation and pyraclostrobin treatments. The wheat plants treated with pyraclostrobin showed a rapidly increased leaf temperature just after treatment but ultimately remained at lower temperatures compared to the control plants which showed a more gradual increase in leaf temperature. Potted soil of the treated wheat plants had higher water contents than the control potted soil, suggesting depression of plant water uptake by pyraclostrobin treatment.

\section{Effect of pyraclostrobin treatment on water uptake of four wheat genotypes}

Mean water uptakes per day for four wheat genotypes were on a per pot and per shoot dry weight in Table 1. Pyraclostrobin treatment decreased water uptake significantly on both a per pot and per dry weight basis. SYN-8 and SYN-10 had the highest and lowest water uptake per dry weight among the four genotypes, showing a genotypic variation.
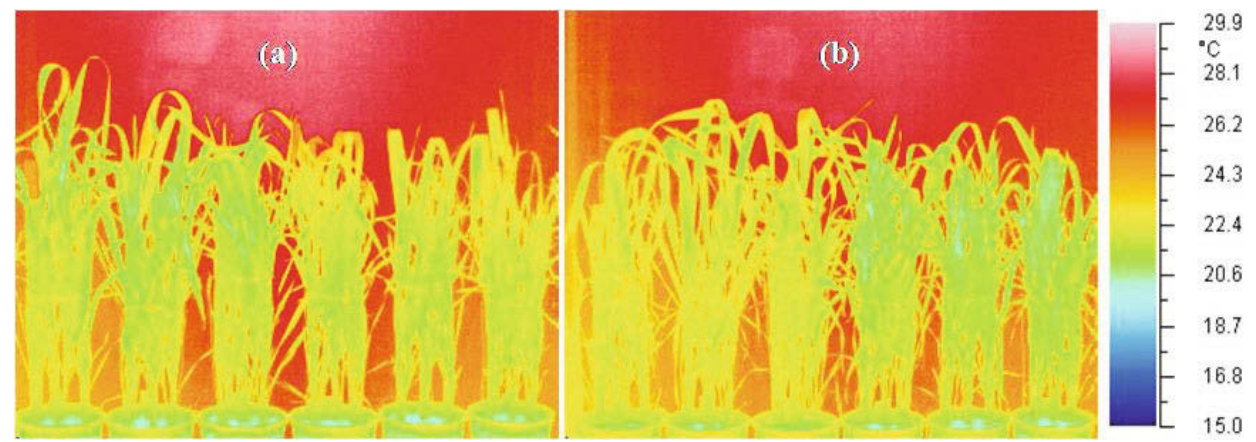

Figure 1. Infrared thermographs of bread wheat cultivar Cham 6 at one day (a) and four days

(b) after treatments of irrigation and fungicide. Untreated control three pots (in left) and treated three pots (in right), respectively

Effect of pyraclostrobin treatment on yield performance of four wheat genotypes grown under increasing water deficit conditions

The total water supply for the whole growing season in the wheat field was $432 \mathrm{~mm}$; rainfall of $223 \mathrm{~mm}$ and irrigation of $209 \mathrm{~mm}$. No incidence of diseases was found in any wheat plots. Mean soil water content over all soil layers decreased gradually from about $30 \%$ at stem elongation to about $20 \%$ at flowering (Fig. 3). Available soil water decreased below the permanent wilting point (29.8\%) during these critical growth stages suggesting that wheat plants grew under soil water deficit before and after flowering. Soil water contents at flowering had a variation among wheat genotypes as expected from differences in water 

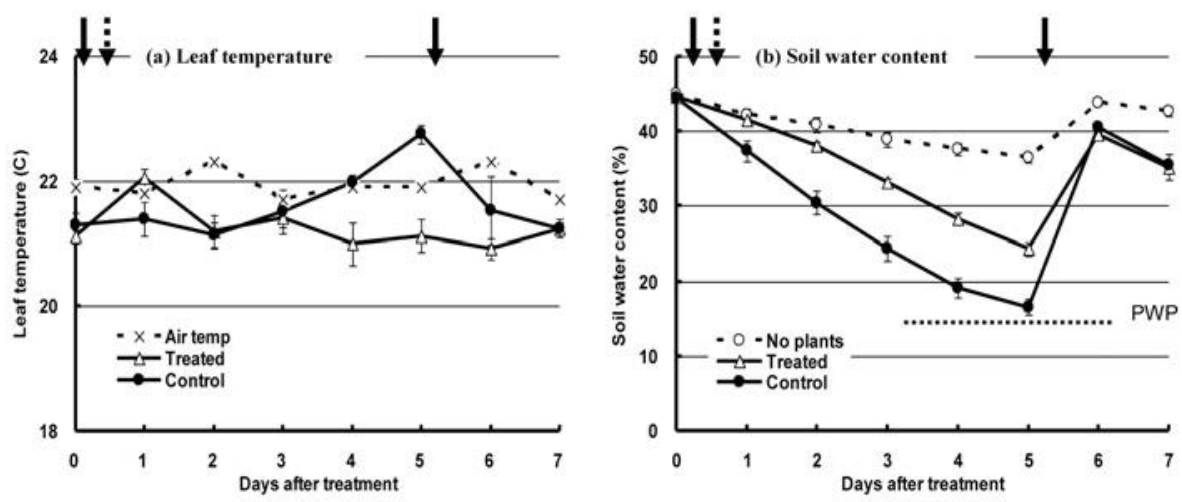

Figure 2. Change of leaf temperature (a) and soil water content (b) for bread wheat cultivar Cham 6 after treatments of irrigation (solid arrows) and fungicide (dotted arrows). Range bars indicate \pm standard deviations of the means

uptake, but did not show distinct differences between pyraclostrobin treatments (Table 2). Differences in canopy temperature at flowering and kernel weight at maturity were also not found (data not shown). There were, however, significant differences in grain yield between treatments and genotypes. Two genotypes, Cham 6 and SYN-10 increased grain yield with pyraclostrobin treatment, but other two genotypes, SYN-8 and SYN-15 having relatively high water uptake and under less soil moisture, did not respond to pyraclostrobin treatment.

Table 1. Water uptake of four wheat genotypes treated with pyraclostrobin

\begin{tabular}{|c|c|c|c|c|}
\hline \multirow{2}{*}{$\begin{array}{l}\text { Wheat } \\
\text { genotype }\end{array}$} & \multicolumn{2}{|c|}{ Water uptake amount $\left(\mathrm{g} \cdot \operatorname{pot}^{-1} \cdot \mathrm{day}^{-1}\right)$} & \multicolumn{2}{|c|}{ Water uptake ability $\left(\mathrm{g} \cdot \mathrm{g}^{-1} \cdot\right.$ day $\left.^{-1}\right)$} \\
\hline & Control & Treated & Control & Treated \\
\hline$\overline{\text { Cham } 6}$ & 44.9 & $34.8^{*}$ & 5.76 & $4.75^{*}$ \\
\hline SYN- 8 & 49.5 & $39.0^{*}$ & 6.50 & $5.38^{*}$ \\
\hline SYN-10 & 38.1 & $29.3^{*}$ & 4.96 & $3.99 *$ \\
\hline SYN-15 & 50.5 & $43.7 *$ & 5.85 & $4.79 *$ \\
\hline LSD $(\mathrm{P}<0.05)$ & \multicolumn{2}{|c|}{3.96} & \multicolumn{2}{|c|}{0.56} \\
\hline
\end{tabular}

ns, *: not significant, significant at $P<0.05$, in comparison with the control.

Table 2. Soil water content at flowering and grain yield in four wheat genotypes treated with pyraclostrobin

\begin{tabular}{|c|c|c|c|c|}
\hline \multirow{2}{*}{$\begin{array}{l}\text { Wheat } \\
\text { genotype }\end{array}$} & \multicolumn{2}{|c|}{ Soil water content $(\%)$} & \multicolumn{2}{|c|}{ Grain yield $\left(\mathrm{g} \cdot \mathrm{m}^{-2}\right)$} \\
\hline & Control & Treated & Control & Treated \\
\hline Cham 6 & 23.5 & $23.2^{\mathrm{ns}}$ & 435 & $470^{*}$ \\
\hline SYN-8 & 22.2 & $22.7^{\mathrm{ns}}$ & 415 & $420^{\mathrm{ns}}$ \\
\hline SYN-10 & 24.8 & $24.2^{\mathrm{ns}}$ & 412 & $470^{*}$ \\
\hline SYN-15 & 22.5 & $22.6^{\mathrm{ns}}$ & 273 & $273^{\text {ns }}$ \\
\hline $\operatorname{LSD}(\mathrm{P}<0.05)$ & \multicolumn{2}{|c|}{1.89} & \multicolumn{2}{|c|}{30.3} \\
\hline
\end{tabular}

ns, *: not significant, significant at $P<0.05$, in comparison with the control. 


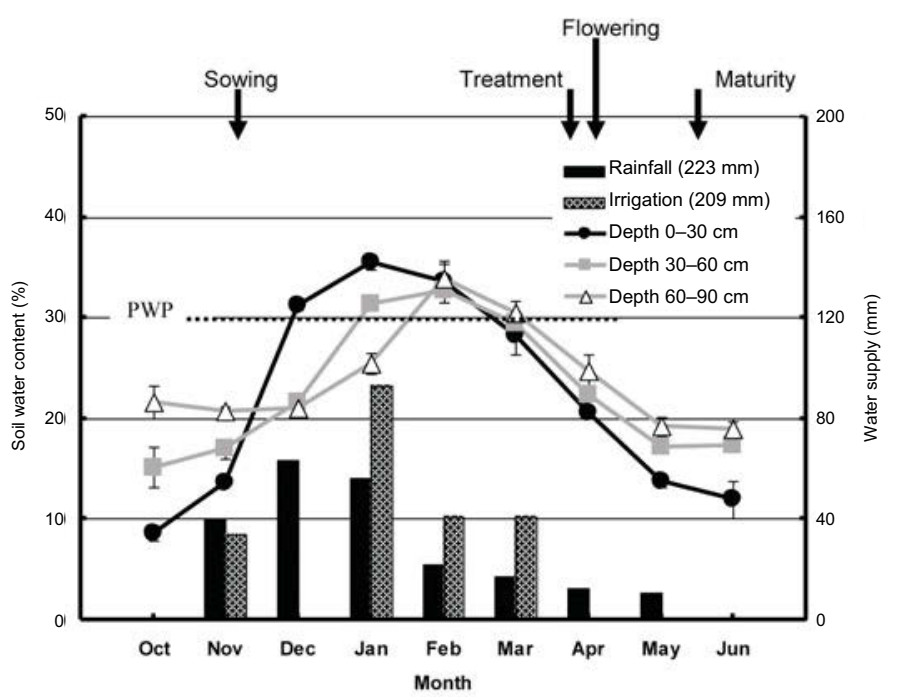

Figure 3. Soil water recharge and discharge in wheat field plots during the experiment. Range bars indicate \pm standard deviations of the means

The experiments in this study could successfully detect changes in both leaf temperature and soil water content immediately after the pyraclostrobin treatment under controlled environmental conditions, but not detect the treatment effects at flowering under field conditions. The effect of pyraclostrobin treated at booting stage might not last till flowering stage. In addition, differences in canopy temperature and soil water content under open field conditions with unpredictable environmental factors are, however, difficult to determine.

It has been previously reported that the foliar pyraclostrobin treatment in wheat had resulted in both the maintenance of green leaf area and the period of grain filling being extended, and thus likely contributing to a yield increase (Gooding et al. 2000; Dimmock and Gooding 2002). Postponement of soil dehydration after pyraclostrobin treatment is considered as one of the favorable effects to increase grain yield in wheat. This hypothesis was partly supported by the results in this study. A field evaluation study of fungicides reported no significant difference in grain yield between the treatments conducted in the high-rainfall zones of Australia (Kleven et al. 2003). Recently it was also reported that foliar treatment of strobilurin fungicides reduced transpiration and improved slightly water status of wheat plants only grown under well-watered conditions (Nason et al. 2007). Yield response to pyraclostrobin treatment may be dependent upon the environmental conditions experienced by the wheat plants.

The results obtained in this study suggest that the foliar application of pyraclostrobin depresses root water uptake, resulting in the postponement of soil dehydration, and finally may contribute to yield enhancement. However, the increase in grain yield by the pyraclostrobin treatment might be dependent on the different water use patterns of the 
wheat genotypes. Further studies on the interaction of the pyraclostrobin dose and the soil water deficit are required to confirm the favorable effect of pyraclostrobin on wheat yield under water stress under controlled conditions.

\section{Acknowledgements}

This report was a contribution from a collaborative research project on "Evaluation of genetic resources and physiological analyses for enhancing drought tolerance in wheat germplasm" between ICARDA and JIRCAS, and supported in part by the fund of BASF SE, Germany.

\section{References}

Bartlett, D.W., Clough, J.M., Godwin, J.R., Hall, A.A., Hamer, M., Parr-Dobrzanski, B. 2002. The strobilurin fungicide. Pest Manage. Sci. 58:649-662.

Del Blanco, I.A., Rajaram, S., Kronstad, W.E. 2001. Agronomic potentials of synthetic hexaploid wheat-derived populations. Crop Sci. 41:670-676.

Dimmock, J.P.R.E., Gooding, M.J. 2002. The effects of fungicides on rate and duration of grain filling in wheat in relation to maintenance of flag leaf area. J. Agri. Sci. 138:1-16.

Dreccer, M.F., Borgognone, M.G., Ogbonnaya, F.C., Trethowan, R.M., Winter, B. 2007. CIMMYT-selected derived synthetic bread wheat for rainfed environments: yield evaluation in Mexico. Field Crops Res. 100:218-228.

Gooding, M.J., Dimmock, J.P.R.E., France, J., Jones, S.A. 2000. Green leaf area decline of wheat flag leaves: the influence of fungicides and relationships with mean grain weight and grain yield. Ann. Appl. Biol. 136:77-87.

Inagaki M.N., Nachit, M.M. 2008. Visual monitoring of water deficit stress using infra-red thermography in wheat, In: Appels, R. et al. (eds), Proceedings of the 11th International Wheat Genetics Symposium 2008, pp.181, Sydney University Press, Brisbane. (URL: http://hdl.handle.net/2123/3452)

Inagaki, M.N., Valkoun, J., Nachit, M.M. 2007. Effect of soil water deficit on grain yield in synthetic bread wheat derivatives. Cereal Res. Commun. 35:1603-1608.

Kleven, S., Dean, G., Hacking, C., Davidson, J. 2003. Evaluation of a new class of fungicides on grain yield in wheat and barley. In: Proceedings of the 11th Australian Agronomy Conference.2003, Australian Society of Agronomy, Victoria. (URL: http://www.regional.org.au/au/asa/2003/p/7/kleven.htm)

Köhle, H., Grossmann, K., Jabs, T., Gerhard, M., Kaiser, W., Glaab, J., Conrath, U., Seehaus, K., Herms, S. 2002. Physiological effects of the strobilurin fungicide F 500 on plants. In: Dehne, H.-W. et al. (eds), Modern fungicides and antifungal compounds III, Mann GmbH \& Co., Bonn, pp. 61-74.

Nason, N.A., Farrar, J., Bartlett, D. 2007. Strobilurin fungicides induce changes in photosynthetic gas exchange that do not improve water use efficiency of plants grown under conditions of water stress. Pest Manage. Sci. 63:1191-1200.

Olivares-Villegas, J.J., Reynolds, M.P., McDonald, G.K. 2007. Drought-adaptive attributes in the Seri/Babax hexaploid wheat population. Funct. Plant Biol. 34:189-203.

Reynolds, M., Dreccer, F., Trethowan, R. 2007. Drought-adaptive traits derived from wheat wild relatives and landraces. J. Exp. Bot. 58: 177-186.

Richards, R.A., Rebetzke, G.J., Condon, A.G., van Herwaadenet, A.F. 2002. Breeding opportunities for increasing the efficiency of water use and crop yield in temperate cereals. Crop Sci. 42:111-121.

Ryan, J., Masri, S., Garabet, S., Diekmann, J., Habib, H. 1997. Soils of ICARDA's agricultural experimental stations and sites: Climate, classification, physiological and chemical properties, and land use. ICARDA, Aleppo, p. 107.

Zhang, H., Oweis, T., Garabet, S., Pala, M. 1998. Water-use efficiency and transpiration efficiency of wheat under rain-fed conditions and supplemental irrigation in a Mediterranean-type environment. Plant Soil 201:295-305.

Cereal Research Communications 37, 2009 